\title{
Chitosan composite films: physicochemical characterization and their use as coating in papaya Maradol stored at room temperature
}

\author{
Miguel Salvador-Figueroa, Dafne Castillo-López, Lourdes Adriano-Anaya, Didiana Gálvez-López, \\ Raymundo Rosas-Quijano, Alfredo Vázquez-Ovando*
}

Instituto de Biociencias, Universidad Autónoma de Chiapas, Boulevard Príncipe Akishino sin número, Colonia Solidaridad 2000, CP 30798, Tapachula, Chiapas, Mexico

\section{A B S T R A C T}

The main objectives of this study were; first formulate and evaluate some properties of chitosan composite films enriched with essential oils of cinnamon, thyme, clove, and lime alone or in combination; and second select the most appropriate formulation and evaluate their effect on physiological properties and fungal incidence of papaya Maradol stored at environmental tropical conditions. Tensile strength, thickness, color, moisture, water vapor permeability, solubility and water sorption of films were measured. Furthermore, in vitro activity was evaluated against Colletotrichum gloeosporioides Penz. Using multivariate analysis and based on the most desirable characteristics (low water sorption values, water vapor permeability, solubility, and greater inhibition of $C$. gloeosporioides), three formulations of films were used lately for coated fruit of papaya Maradol and stored at $28 \pm 3{ }^{\circ} \mathrm{C}$ and $85 \% \mathrm{RH}$. Two control treatments were included: one uncoated and other treated with Mancozeb ${ }^{\circledR}$ fungicide. At six days of storage, the fruit of both control treatments showed evident signs of ripening; contrary to the treatments wherein fruit were coated, and had low respiration, other attributes as firmness, little change in the external color of the fruit were manifested. Similarly, the use of composite films reduced the fungus C. gloeosporioides by $30-50 \%$. The use of film enriched with essential oil of $1 \%$ cinnamon- $1 \%$ thyme improved the characteristics of fruit quality, increased shelf life and reduced by $50 \%$ the incidence of fungus in papaya Maradol stored under humid tropic environmental conditions. This coating can be an alternative to potentially reduce the need for cold storage during postharvest handling.

Keywords: Antifungal coating; Colletotrichum gloeosporioides; Inhibition; Water vapor permeability; Respiration; Firmness; Peel color

\section{INTRODUCTION}

Losses in post-harvest period for fruits and vegetables can consume up to $85 \%$ of production, especially in developing countries (Cissé et al., 2015). The presence of fungi pathogens is one of the main postharvest problems, especially in tropical regions. The papaya is an example of fruit which is exposed directly to this problem. The development of pathogenic fungi in papaya e.g. Colletotrichum gloeosporioides that causes anthracnose reduces significantly the postharvest life and alters the fruit quality and sensory characteristics. The use of low temperatures (refrigeration) is the main strategy to reduce the presence of these pathogens, as well as delaying the ripening process; however, for small growers and merchants, this process is difficult to implement because of the costs involved in installation and operation (Liu et al., 2012).

Synthetic fungicides are the most widely used to enhance postharvest quality of fruit; however, the excessive uses are associated with fungicide toxicity, environmental pollution, development of fungicide resistance in pathogens, and potential risks to human health; consequently, new alternative strategies for reducing postharvest disease are required (Hu et al., 2014). The uses of gamma radiation (Rashid et al., 2015) or electromagnetic radiation as UV-C (Cia et al., 2007) are other options; nevertheless, these applications implicate infrastructure and high costs being an undesirable implementation for small producers.

\footnotetext{
*Corresponding author:

Alfredo Vázquez-Ovando, Instituto de Biociencias, Universidad Autónoma de Chiapas. Boulevard Príncipe Akishino sin número, Colonia Solidaridad 2000, CP 30798. Tapachula, Chiapas, Mexico. Phone: +52 9626427972. E-mail: jose.vazquez@unach.mx
} 
As strategies less dependent on infrastructure, it has been implemented the use of coatings or films made from natural polymers (Ali et al., 2011). Further, these polymers have been mixed with essential oils from different sources (Sivakumar \& Bautista-Baños, 2014). These composite films reduce and even eliminate the presence of pathogenic microorganisms; furthermore, these applications increase the shelf life of fruits and vegetables acting as a semipermeable covering, partially modifying the micro-atmosphere of the fruit and delay ripening (Dotto et al., 2015). The effects of many polymers used for this purpose have been evaluated on the physicochemical and biological properties of fruits and vegetables. However, due to that chitosan as biodegradable, edible, compatible with other molecules, non-toxicity and antimicrobial (antibacterial and antifungal activities), the coatings made with chitosan are the most studied (Keqian et al., 2012). Their coatings have been used in different fruits to increase the shelf life and other physicochemical characteristics of the fruits (Salvador-Figueroa et al., 2011; Keqian et al., 2012; Kaya et al., 2016).

On the other hand, it has been reported that, in addition to improving the post-harvest quality of the fruits, the addition of essential oils of several plants in the films provides an efficient antifungal capacity to the films (Bosquez-Molina et al., 2010, Lopez-Reyes et al., 2013). Some reports emphasize the importance of evaluating the changes in the physical, mechanical or antifungal properties of biofilms when essential oils are incorporated (Sánchez-González et al., 2011b; Peng \& Li, 2014; Ma et al., 2016). Even with the preceding, a small number of studies focus on evaluating the effectiveness of this combination of strategies on climacteric fruit or fruit with high susceptibility to the fungi presence. By the papaya fruit characteristics, as fast physiology and soft texture peel become a suitable environment for several fungi development; moreover, the shelf life of mature green ranges from 5-7 days at the environmental conditions of the humid tropics without postharvest treatment (Singh and Sudhakar, 2011).

The use of chitosan enriched with essential oils as a coating on fruits has been extensively documented, but most reports use it as a combined strategy with cold storage for tropical and subtropical fruits, or; for non-climatic fruit, temperate fruit, or under boreal environmental; the effect of combination of two or more different essential oils into chitosan films properties is scarcely known. Therefore, the main objectives of this study were; 1 ) to assess the physical and antimicrobial properties of chitosan films enriched with essential oils of thyme, cinnamon, cloves and lime and; 2) use these coatings and evaluate their effect in the fruit shelf life of Carica papaya L. Maradol stored at room temperature of humid tropic.

\section{MATERIALS AND METHODS}

\section{Reagents}

Low molecular weight chitosan (75-85\% deacetylation grade), glacial acetic acid and Tween 20 (Sigma-Aldrich ${ }^{\circledR}$ ) were used. The essential oils of cinnamon (Cinnamomum zeylanicum), thyme (Thymus vulgaris), clove (Eugenia caryophyllata) and lime (Citrus aurantifolia) were from Meyer ${ }^{\circledR}$ reagents. The potato dextrose agar (PDA) used was Sigma-Aldrich ${ }^{\circledR}$. All chemicals used were reagent grade.

\section{Treatments}

Two treatments groups were formed under a full $2^{4}$ factorial design (16 treatments per group). The group formation criterion was the final total concentration of essential oil in the biofilm. Treatments of the first group contained $1 \%$ (individually or combined with two, three, and/or four essential oils) and the second with all the same criteria described but a final concentration of $2 \%$ of essential oils. The four factors tested were essential oils of clove, cinnamon, thyme, and lime, and the levels were absence/ presence of the corresponding essential oil. A total of 31 different treatments were formulated, since the control treatment without essential oils (only chitosan, Ch) is present in both groups $(1 \%$ and $2 \%)$ of treatments (Table 1).

\section{Preparation of films}

To prepare the films, the procedure described by Binsi et al. (2013) was followed, with modifications. First, the chitosan $(1.5 \% \mathrm{w} / \mathrm{v})$ was dissolved in an aqueous acetic acid solution $(1 \% \mathrm{v} / \mathrm{v})$ using magnetic stirrer at $45^{\circ} \mathrm{C}$ for $24 \mathrm{~h}$. The solution was cooled to room temperature; $0.5 \%$ (v/v) of Tween 20 was added and then homogenized by magnetic stirring for $2 \mathrm{~h}$. From this solution, a volume of $20 \mathrm{~mL}$ was used to formulate each mixture set (see section on treatments of Table 1). Immediately after the addition of essential oils, the mixture was subjected to ultrasonication for $5 \mathrm{~min}$ in an Ultrasonic Processor ${ }^{\circ}$ VCX 500 (500 W, $20 \mathrm{kHz}$ ) sonicator, $13 \mathrm{~mm}$ tip, $60 \%$ amplitude; $50 \mathrm{~s}$ of sonication and $10 \mathrm{~s}$ of inactivity, in order to achieve the formation of a microemulsion. After homogenization, $3 \mathrm{~mL}$ of solution were poured into sterile Petri dishes $(60 \mathrm{~mm}$ diameter) and then allowed to stand $\left(28^{\circ} \mathrm{C}\right.$ for $48 \mathrm{~h}$ ) until the formation of a film. The films thus formed were individually stored at $4{ }^{\circ} \mathrm{C}$ in hermetically sealed polyethylene bottles until their analysis.

\section{Characterization of the films Physical properties}

The force required to cause a rupture (TS, tensile strength) was determined by use a hand penetrometer (TR ${ }^{\circledR}$ Italy) equipped with a tip of $5 \mathrm{~mm}$ in diameter, and estimated according to the equation $\mathrm{TS}(\mathrm{MPa})=\mathrm{N} / \mathrm{mm}^{2}$. Film thickness $(\mu \mathrm{m})$ was measured with a digital micrometer $\left(\right.$ Fowler $\left.^{\circledR}\right)$; the 
Table 1: Content (\%) of each oil essential added to chitosan film of different formulations

\begin{tabular}{|c|c|c|c|c|c|}
\hline Treatment code & Cinnamon (C) & Clove $(\mathrm{Cl})$ & Lime (L) & Thyme (T) & Final content \\
\hline Control (Ch) & 0 & 0 & 0 & 0 & 0 \\
\hline CCITL1 & 0.25 & 0.25 & 0.25 & 0.25 & 1 \\
\hline CCIL1 & 0.33 & 0.33 & 0.33 & 0 & 1 \\
\hline $\mathrm{CCl} 1$ & 0.5 & 0.5 & 0 & 0 & 1 \\
\hline C1 & 1 & 0 & 0 & 0 & 1 \\
\hline $\mathrm{Cl} 1$ & 0 & 1 & 0 & 0 & 1 \\
\hline L1 & 0 & 0 & 1 & 0 & 1 \\
\hline $\mathrm{T} 1$ & 0 & 0 & 0 & 1 & 1 \\
\hline CITL1 & 0 & 0.33 & 0.33 & 0.33 & 1 \\
\hline TL1 & 0 & 0 & 0.5 & 0.5 & 1 \\
\hline CT1 & 0.5 & 0 & 0 & 0.5 & 1 \\
\hline CIL1 & 0 & 0.5 & 0.5 & 0 & 1 \\
\hline CTL1 & 0.33 & 0 & 0.33 & 0.33 & 1 \\
\hline CL1 & 0.5 & 0 & 0.5 & 0 & 1 \\
\hline CCIT1 & 0.33 & 0.33 & 0 & 0.33 & 1 \\
\hline CIT1 & 0 & 0.5 & 0 & 0.5 & 1 \\
\hline CCITL2 & 0.5 & 0.5 & 0.5 & 0.5 & 2 \\
\hline CCIL2 & 0.66 & 0.66 & 0.66 & 0 & 2 \\
\hline $\mathrm{CCl} 2$ & 1 & 1 & 0 & 0 & 2 \\
\hline C2 & 2 & 0 & 0 & 0 & 2 \\
\hline $\mathrm{Cl} 2$ & 0 & 2 & 0 & 0 & 2 \\
\hline L2 & 0 & 0 & 2 & 0 & 2 \\
\hline $\mathrm{T} 2$ & 0 & 0 & 0 & 2 & 2 \\
\hline CITL2 & 0 & 0.66 & 0.66 & 0.66 & 2 \\
\hline TL2 & 0 & 0 & 1 & 1 & 2 \\
\hline CT2 & 1 & 0 & 0 & 1 & 2 \\
\hline CIL2 & 0 & 1 & 1 & 0 & 2 \\
\hline CTL2 & 0.66 & 0 & 0.66 & 0.66 & 2 \\
\hline CL2 & 1 & 0 & 1 & 0 & 2 \\
\hline CCIT2 & 0.66 & 0.66 & 0 & 0.66 & 2 \\
\hline CIT2 & 0 & 1 & 0 & 1 & 2 \\
\hline
\end{tabular}

color of the films with a colorimeter (MiniScanEZ 4000S), and the values reported as $L^{*}, a^{*}, b^{*}$ of the CIE Lab scale. The water vapor transmission rate (WVTR) was measured by the method suggested by Ulbin-Figlewicz et al. (2014) and the water vapor permeability (WVP) was calculated with the formula: WVP $(\mathrm{g} / \mathrm{m} \mathrm{s} \mathrm{kPa})=($ WVTR $L) / \Delta P$, where " $L$ " is the film thickness (m) and " $\Delta P$ " is the differential of partial pressure between the two sides of the biofilm $(3.179 \mathrm{kPa})$. Solubility $(\mathrm{S})$ was determined according to a method proposed by Wang et al. (2011) and; the water content retained in equilibrium by the method described by Binsi et al. (2013), which is reported as water sorption capacity (WSC). For each treatment, five replicates were independently developed and evaluated, considering one film as a replicate.

\section{Antifungal activity in vitro}

For in vitro evaluation of the antifungal activity of the films, $50 \mu \mathrm{L}$ of spore suspension $\left(10^{9}\right.$ spores $\left./ \mathrm{mL}\right)$ were dispersed in Petri dishes containing medium PDA. Subsequently, eight disks ( $5 \mathrm{~mm}$ diameter) of different treatment films were placed on the surface. The plates were incubated at $25^{\circ} \mathrm{C}$, every $24 \mathrm{~h}$ mycelial growth was observed, and the diameter was measured at various points of the zone of inhibition present around the film (Pereira et al., 2013). For this, the plates were visualized under a stereoscope (ZEIZZ®), a photographic record was made with a high definition camera, and then the areas of the film and the inhibitory perimetral area were determined by the ZEN 2011 program. For each biofilm, five replicates were performed.

\section{Shelf life of coated fruit}

In order to evaluate the shelf life of coated papaya fruit, the best treatment outcomes were chosen, according to with characteristics as growth inhibition (perimeter area) and film texture. Thus three treatments were selected and applied to Maradol papaya fruit: C2) $2 \%$ cinnamon, CT2) $1 \%$ cinnamon-1 $\%$ thyme and CL2) $1 \%$ cinnamon-1 $\%$ lime.

\section{Evaluation in situ of coatings}

Fruit of Carica papaya cv. Maradol $(\mathrm{N}=300)$ were acquired from growers of Tapachula, Chiapas, Mexico. These were conventionally cultured, harvested in the physiological 
maturity, free of physical damage and all chosen of a uniform size (approximately $1.5 \mathrm{~kg}$ ). Under a completely randomized design, the fruits were divided into groups of 60. Three groups for each of the treatments of previously selected films, and two for control treatments (one without application of coatings and one with the application of fungicide Mancozeb $^{\circledR}$ ). All the fruit were washed in tap water, immersed for $3 \mathrm{~min}$ in $200 \mathrm{ppm}$ sodium hypochlorite aqueous solution (Oliveira et al., 2016) and allowed to dry at room temperature. Chitosan solutions containing essential oils were applied manually to the corresponding fruit with the use of a polyurethane foam brush. Subsequently, they were dried with fan blades for one min. The synthetic fungicide solution $(3 \mathrm{~g} / \mathrm{L}$ of active ingredient) was also applied with a polyurethane brush. All the fruit were stored in polypropylene containers, in a closed warehouse at room temperature $\left(28 \pm 3{ }^{\circ} \mathrm{C}\right)$ and $85 \pm 5 \% \mathrm{RH}$.

\section{Quality characteristics assessment on fruit}

For quality characteristics assessment, each $24 \mathrm{~h}$, five fruit per treatment were randomly selected and evaluated, starting from the application coatings day (day 0), until ten days. The firmness was determined by the required force in Newtons $(\mathrm{N})$, to penetrate the pericarp with a digital penetrometer $\mathrm{TR}^{\circledR}$ (Italy) provided with a conical plunger of $10 \mathrm{~mm}$ of diameter (AOAC, 2010). The peel and pulp color were determined with a colorimeter (MiniScanEZ 4000S) based on the system of CIEL, a*, b*. Firmness and peel color measurements were made near the peduncle, in the middle of the fruit and in the pedicel. The total soluble solids ( ${ }^{\circ} \mathrm{Brix}$ ) were determined at $22{ }^{\circ} \mathrm{C}$, with a digital refractometer ATAGO, Model PAL- $\alpha$ (Japan) using 2 to 3 drops of juice obtained by squeezing the pulp (AOAC, 2010) and the result reported as a percentage. To determine the titratable acidity of the fruit, $10 \mathrm{~g}$ of the pulp of each fruit were first diluted with sterile distilled water to achieve $50 \mathrm{~mL}$. Ten $\mathrm{mL}$ of the dilution were then titrated with $0.1 \mathrm{~N} \mathrm{NaOH}$ (AOAC, 2010). Results were expressed as a percentage of citric acid. Weight loss of fruit was determined using a digital scale (Ohaus ${ }^{\circledR}$ CS Compact scales ${ }^{\mathrm{TM}}$ Model CS2000P; USA), referencing to the initial and final weights of the fruit and then results were reported as a percentage of weight loss (AOAC, 2010). Furthermore, $\mathrm{CO}_{2}$ production (respiration) was measured placed 2 fruit in a sealed container $(7 \mathrm{~L})$ for $2 \mathrm{~h}$, after this time, the $\mathrm{CO}_{2}$ amount was recorded by the IAQ-CALC $\left(\mathrm{TSI}^{\circledR}\right.$ ) probe and reported as $\mathrm{mg} / \mathrm{kg} \mathrm{s}$ (Salvador-Figueroa et al., 2011).

\section{Fungi incidence and severity index}

The fungi injury was measured as incidence (\%) and severity index using scale $0-4$, both of using the procedures suggested by Bosquez-Molina et al. (2010).

\section{Data analysis}

Comparisons between treatments were conducted using univariate ANOVA followed by Duncan's multiple range test $(\alpha=0.05)$. In addition, to cluster treatments and locate film formulations with the most appropriate characteristics to be used as coatings, all variables were subjected to multivariate statistics using the Hierarchical Ascendant Classification (HAC) test; and based on the dissimilarity of Euclidean distance, a dendrogram was constructed by the agglomeration method of Ward. All analyses were computed by Infostat Professional C v2011 statistical program.

\section{RESULTS AND DISCUSSION}

\section{Physical properties of the films}

All variables data performed to determine the film efficiency are shown in Table 2. The tensile strength evaluated in treatments ranged from 26.53 to $60.94 \mathrm{MPa}$, the fewer strength films being those where essential oils of cinnamon and thyme (in both tested concentrations) were incorporated in combination, and also the films that containing only chitosan (Ch). The values for control treatment $(\mathrm{Ch})$ was found within the range reported by others (Casariego et al., 2009, Wang et al., 2011, López Mata et al., 2013, 10-51 MPa) for chitosan films, this behavior is linked to several factors such as the chitosan concentration, the degree of acetylation of the molecule, and several others. Contrary to what occurred in combined essential oils, when they were incorporated individually at both $1 \%$ and $2 \%$, the films were firmest, as it was with TL1 treatment. These results are consistent with the significant effect of oil essential as a factor on the strength of the film revealed by the analysis (data not shown), where cinnamon $(p<0.0001)$, lime $(p=0.0026)$ and thyme $(p<0.0001)$ oils were incorporated. This highlights the positive effect of films combined with essential oils on film strength. Indeed, several studies report that the oil addition on films reduces the matrix strength when they are combined (Pereda et al., 2012, Binsi et al., 2013, López-Mata et al., 2013). However, in concordance with our findings, it has been reported that the addition of olive oil improves the tensile properties of chitosan films (Pereda et al., 2012).

All films tested demonstrated a smooth appearance without any visible cracks or pores in the surface. The control films (Ch) had an average thickness of $55.88 \pm 1.08 \mu \mathrm{m}$. Treatments combined with essential oils, the film thickness was significantly modified $(\phi<0.05)$ obtaining values in the range of 47.41 to $72.81 \mu \mathrm{m}$. Therefore, results indicate that adding essential oils significantly changed the film thickness, as factor analysis revealed $p$-values $<0.01$ for all essential oil. The combination of various essential oils resulted in 


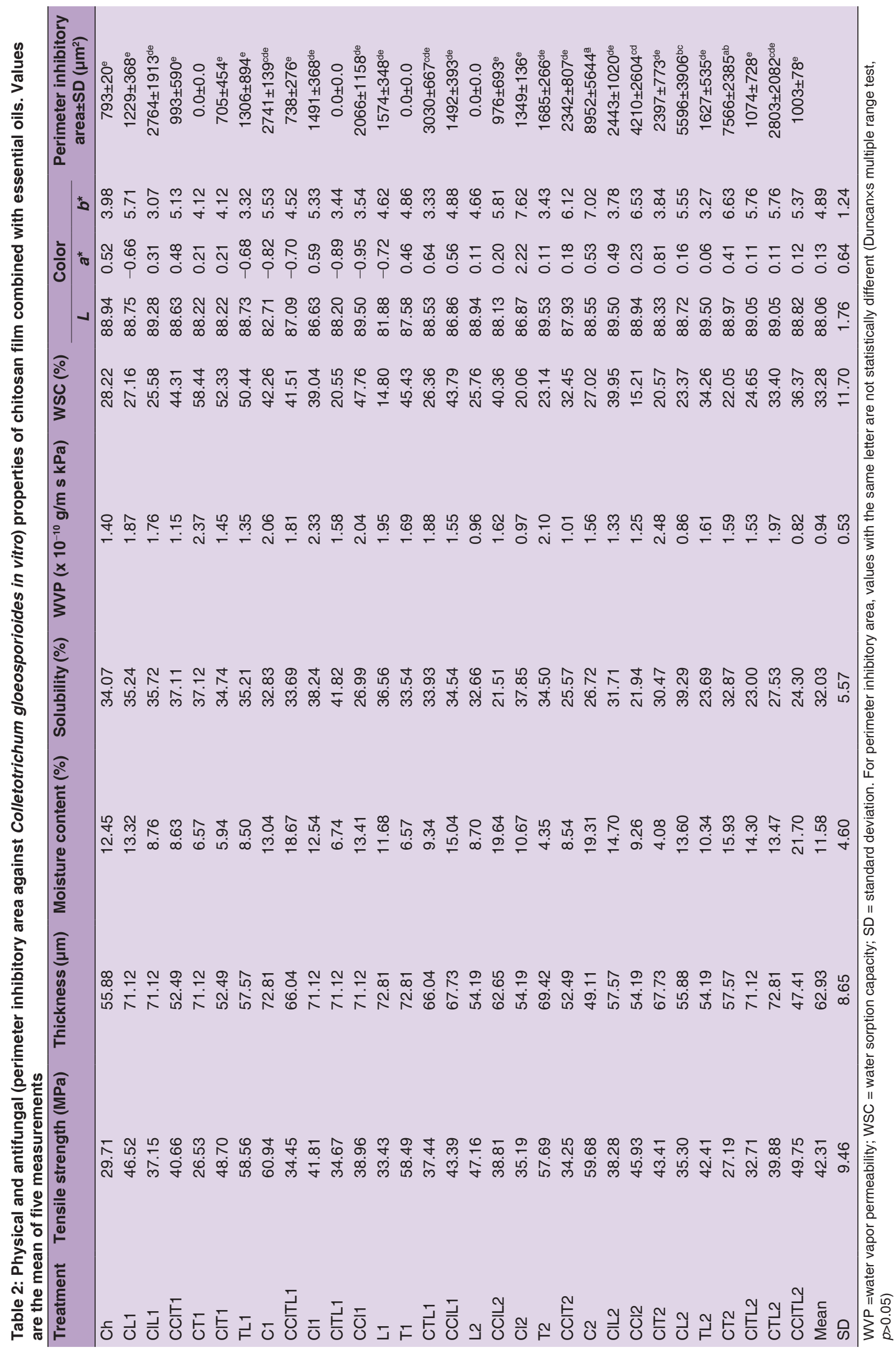


thinner films, being the cinnamon oil the common factor; in contrast, films with only one essential oil were those of greater thickness. This agrees with results reported by Binsi et al. (2013), who reports the thickness of $60 \pm 2 \mu \mathrm{m}$ for chitosan films, and values similar to our results in films combined with coconut oil. The variables that most affect the thickness of the film are the interactions, alignment and compactness of chitosan molecules during the process of forming and drying the resulting film (Binsi et al., 2013). That suggests that addition of essential oils modify some of these characteristics due to possible electrostatic interactions chitosan-essential oils.

Moisture content for all treatments ranged from 4.08 to $21.70 \%$. The films made with only chitosan (Ch) presented a mean value of $12.45 \pm 3.80 \%$. Films containing less water had clove and thyme oils in common, while those which retained more water had in common cinnamon and clove oils essential. However, only the essential oil of cinnamon had a significant effect as factor $(p=0.013)$ on solubility. Generally, the reported values for all treatments are low when compared to other studies where chitosan films combined with oils are used together, as values are reported between $12.72 \%$ (Bourbon et al., 2011) and $51.30 \%$ (Wang et al., 2011). The moisture content is directly associated with solubility, which is an important variable because in many cases, higher solubility is desired which is associated with the film degradation of the film, mainly in almost ready to eat foods. Conversely, low values of solubility (and moisture) are desirable in search of films that present higher strength and low rate of mass transfer (water vapor, gasses) (Wang et al., 2011). The solubility values obtained ranged from 21.51 to $41.82 \%$. Films of the treatments with a concentration of $2 \%$ of oils essential were less soluble than those containing $1 \%$.

The above results are consistent with expectations partially, because the chitosan films (Ch) are presumed to present the highest values of humidity and solubility; this by dissolving the chitosan in acetic acid, where the cationic character of the molecule is increased and consequently would promote greater hydrophilicity (Binsi et al., 2013). Thus, the added oils would promote interactions chitosan-oil, which have a strong hydrophobic character. However, in our study higher values of the moisture content and solubility were obtained in several treatments containing essential oils with respect to control $(\mathrm{Ch})$. This event can be explained because molecular interactions of oil-oil (one or more oils), oil-chitosan, on coming into contact with water may lose system microstructure (forming micropores) and allow entry and entrapment of water, as has been shown occurs in chitosan films enriched with $1 \%$ of thyme oil (Hosseini et al., 2009).
The permeability of a film is a determinant factor for deciding their potential use, such as measuring the amount of water vapor that can pass through the materials that constitute the film. The treatments evaluated were in a wide range of 0.82 to $2.48 \times 10^{-10} \mathrm{~g} / \mathrm{m} \mathrm{s} \mathrm{kPa}$, while films of chitosan (Ch) exhibited an average value of $1.40 \times 10^{-10} \mathrm{~g} / \mathrm{m} \mathrm{s} \mathrm{kPa}$. Although none of the essential oils had a statistically significant effect ( $p$-values $>0.05$ for all treatments), the treatments containing essential oil of thyme showed the highest values of WVP (Table 2). However, this is not desirable in a film, because the main reason to use as a coating is having desirable lowest values due their effect as barriers (Wang et al., 2011). Chitosan, as pointed out before, is by nature cationic, which means more interaction with water molecules and consequently increased WVP. The essential oils of clove and cinnamon, while not showing significance as a factor $(p>0.05)$ tended to show lower values of WVP in the films where they were included, as has been reported to occur by incorporating coconut oil into chitosan films (Binsi et al., 2013). This is due to minimizing the availability of active groups for the chitosan-water interactions, and the matrix becomes more hydrophobic, making the film compact, less permeable, and with lower porosity.

Something quite similar occurs with the water sorption capacity of the films. However, for this variable, a significant effect can be seen from oils of cinnamon, lime, and thyme. Films containing oils of thyme showed the highest values in the WSC, in contrast to the films where essential oil of cinnamon and lime was added, the values were lower in line with those reported by other authors (Binsi et al., 2013). This may be in consequence of the terpene content of essential oil of thyme (mainly cymene and thymol) which forms weak bonds with chitosan, making the structure more porous and permeable, favoring both the WVP and the WSC (Hosseini et al., 2009). In our study, rates $14.8 \%$ lower were found compared with others reported, which lets the marked effect of the addition of oils on this variable.

The parameters used for assessing the color $\left(L^{*}, a^{*}\right.$ and $\left.b^{*}\right)$ were not significantly affected by the addition of any of the essential oils. In general, all the films were transparent. The brightness remained in a tight range (Table 2), which is highly desirable for materials used as coatings for food due these do not affect the natural color of the fruit. $a^{*}$ and $b^{*}$ values showed variations that gave weak yellowish aspects on films, but not enough to show a significant effect of any factor (essential oil) in particular ( $p>0.05)$. It has been reported that the addition of coconut oil decreases the parameters $L^{*}, a^{*}, b^{*}$ (Binsi et al., 2013), that coincides with the addition of some essential oils. The color values obtained for the control film (Ch) were $L^{*}=88.94, a^{*}=0.52$ and $b^{*}=3.98$, different from those 
reported by Casariego et al. (2009) which can be explained due on this study were used chitosan with different degree of acetylation and different molecular weight.

\section{Effect of essential oils on the in vitro growth of Colletotrichum gloeosporioides}

The inhibition perimeter areas for in vitro growth of C. gloeosporioides produced by chitosan films alone, and with essential oils incorporated, are shown in Table 2. In general, the inhibitory effect of chitosan (Ch treatment) is only shown greater on films treatments combined with thyme oil $(1 \%)$, cinnamon-thyme $(0.5 \%: 0.5 \%)$, clove-thyme $(0.5 \%: 0.5 \%)$, clove-thyme-lime $(0.33 \%: 0.33 \%: 0.33 \%)$, cinnamon-clove-thyme-lime $(0.25 \%: 0.25 \%: 0.25 \%$ : $0.25 \%)$ and lime $(2 \%)$. These results reveal a marked negative impact of addition of thyme essential oil on the growth inhibition of the fungus, at least at concentrations below of $1 \%$, being that for various treatments that contain this essential oil the inhibition was zero. Previous studies have shown a strong antagonistic activity of thyme essential oil against undesirable bacteria (Hosseini et al., 2009). However, it is shown that this is not the case with the fungus evaluated here, which could be explained due to when the thyme essential oil is mixed with Tween ${ }^{\circledR}$, then the antifungal capacity decreases significantly as was previously reported (Zeng et al., 2015).

Contrary to this, values of more than $5596 \mu \mathrm{m}^{2}$ were found in the inhibition area for the cinnamon treatment $(2 \%)$, cinnamon-lime $(1 \%: 1 \%)$ and cinnamon-thyme
$(1 \%: 1 \%)$, the same exhibited significant differences $(p<0.05)$. It is noteworthy that the highest concentrations of oil (2\%), except lime oil only, that have the highest values of inhibition, than its counterpart at $1 \%$, which is consistent with that reported by Perez-Espitia et al. (2012) and Bosquez-Molina et al. (2010), that the fungicidal action increases as the concentration of essential oils increases. This shows that the effect of major compounds responsible for the antimicrobial activity of various essential oils (cinnamaldehyde, linalool, eugenol and cineol in cinnamon oil; limonene, beta-pinene, and citral in lime oil) was not diminished or nullifies by interactions with components of the chitosan matrix.

\section{Multivariate analysis of films parameters}

The individual data analysis of characteristics of the film (ANOVA tests and means comparisons) made it difficult to interpret in general in order to decide and select the treatments with the most promising results to be used as coatings on papaya fruit. Therefore, a multivariate analysis was performed; and employing both the physicochemical characteristics as well as the inhibition of the fungus, a cluster analysis was performed, and then, based on the Euclidean distance (Figure 1) a dendrogram was constructed. From the analysis, four clusters (C1-C4) were obtained, these grouped all 31 treatments. Eight treatments were grouped in C1, 11 treatments grouped as C2, C3 for 9 treatments, while $\mathrm{C} 4$ grouped only 3 treatments (bottom, Figure 1) which were markedly dissimilar (> 4000) of the other clusters.

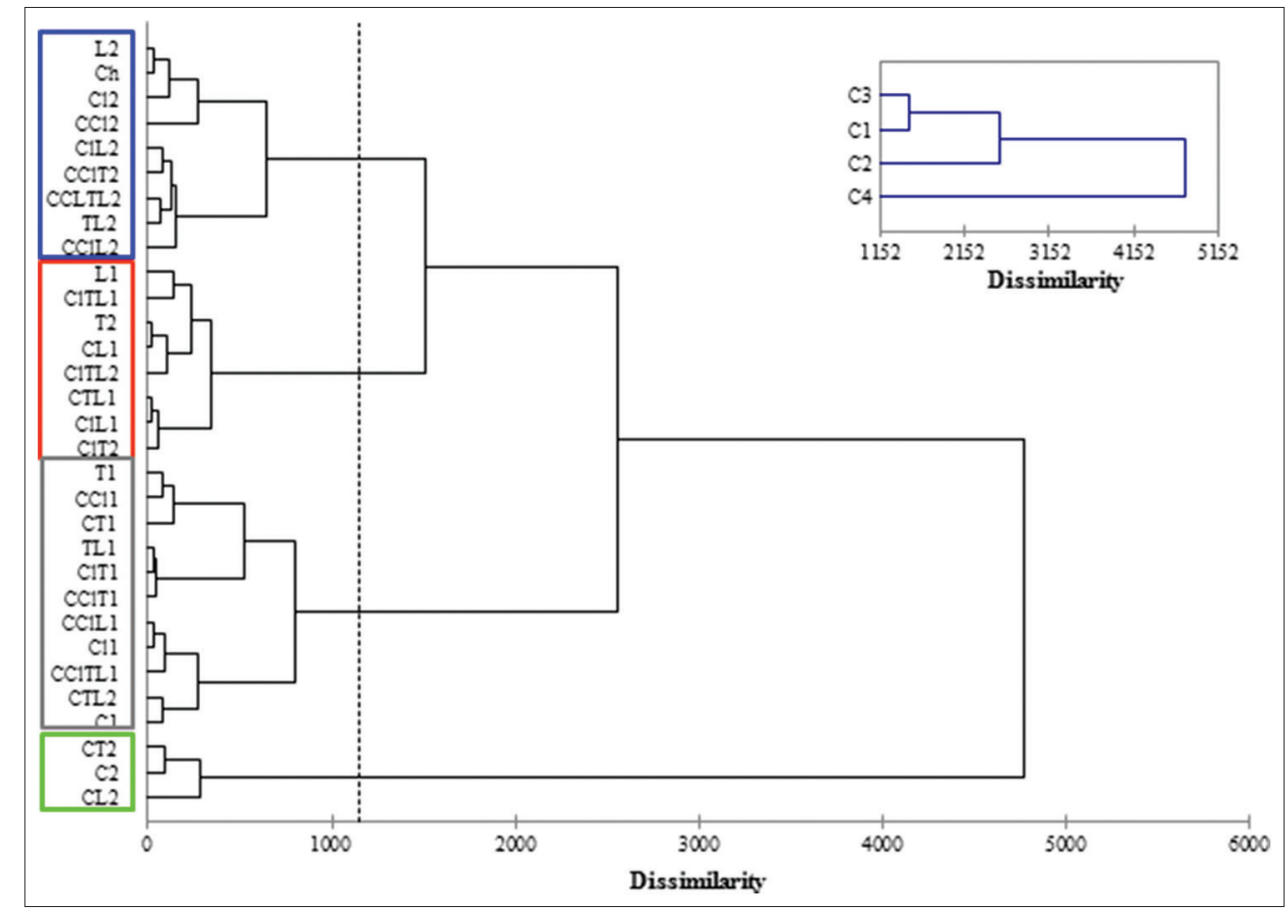

Fig 1. Dendrogram of 31 treatments constructed with data measurements for physicochemical variables and inhibition of mycelial growth of C. gloeosporioides. 
The three treatments grouped in C4 were those containing $2 \%$ of essential oils and which presented the largest growth inhibition for C. gloeosporioides, which denotes a strong contribution of this variable to multivariate analysis (Table 2). For these results, it can be observed that for almost all variables, the values are suitable, as described before, for use as coatings; i.e. low values for: water sorption, water vapor permeability, and solubility; intermediate values for the thickness; and high values in resistance, but especially the inhibition of mycelial growth of the fungus tested. Therefore, these treatments were selected to be applied on papayas as coatings.

\section{Physiological characteristics of coated papaya fruit}

The application of different chitosan-based coatings on papaya cv. Maradol fruit did not adversely alter the physiological parameters of the normal ripening. For weight loss, total soluble solids content, and titrable acidity, no difference was found between treatments $(p>0.05)$, and the variations observed (Fig. 2) are the results of variability between fruit and the natural ripening process.

Conversely, respiration (amount of $\mathrm{CO}_{2}$ produced) did show differences between treatments for several days (Fig. 2). In general, the content of $\mathrm{CO}_{2}$ is similar to those reported for this papaya variety stored at $23{ }^{\circ} \mathrm{C}$ and $70 \%$ RH (Santamaría-Basulto et al., 2009), and even for other varieties. During the first two storage days, respiration was similar between coated fruit and those that were not coated, demonstrating that the coatings did not exert stress to the fruit (gasses accumulation) subsequent to being coated. From the third day, differences between treatments were evident, becoming significant differences $(p<0.05)$ on the sixth day. The two control treatments (without the coating and with the application of Mancozeb ${ }^{\circledR}$ ) showed by the fifth day the more pronounced respiratory rise, being coincident with changes taking place in the fruit for the parameters of firmness on the $6^{\text {th }}$ day (Fig. 2) and external and internal color (Fig. 3 and 4). The fruit with cinnamon and cinnamon-lime coatings diminished the respiratory peak with similar values to control treatment $\left(\sim 4.5 \times 10^{-3} \mathrm{mg} / \mathrm{kg} \mathrm{s}\right.$ of $\left.\mathrm{CO}_{2}\right)$ on $8^{\text {th }}$ storage day. Chitosan coating with essential oils of cinnamon-thyme reduced the burst of papaya fruit respiration to values of $\mathrm{CO}_{2}$ content below $3.5 \times 10^{-3} \mathrm{mg} /$ $\mathrm{kg} \mathrm{s}$ during the 10 days of the experiment. Since there is no evidence of the effect that essential oils can exert directly on the respiratory physiology of the fruit, it is only possible to think that the appearance of the respiratory peak was delayed beyond the 10 days studied. This can be due to a direct effect of the change in the gas transfer due to the coating or, as an indirect consequence of the reduction of stress given by the low incidence of fungi that presented the fruits of cinnamon $1 \%$ thyme $1 \%$ (Table 3 ).

On the other hand, the peel color, which is the first visual attribute evaluated on fruit, exhibited for all treatments evaluated here a behavior dependent on the treatment. Thus, during the first three days of storage at room temperature, all treatments showed statistically similar and equal values for $L^{*}$ and $a^{*}(p>0.05)$ parameters. From the $2^{\text {nd }}$ day $\left(\right.$ value $\left.b^{*}\right)$ and the $4^{\text {th }}\left(L^{*}, a^{*}\right)$ treatments which had no coating showed a gradual change of values to shades of yellow-orange (Fig. 3 A-C) characteristic of ripe fruit (Fig. 4). During the 10 days of storage, the parameters of external color remained almost unchanged for the three treatment coatings. Although this same phenomenon was also observed with the internal aspect (Fig. 4), the values of $L^{*}, a^{*}, b^{*}$ of internal color were very similar for all the treatments and no significant variations during storage was observed (Fig. 3 D-F).

The fact that chitosan coatings containing essential oils only had effect on respiration, firmness, and color, this may be due to the effect of essential oils on the physiological processes involved in the degradation of molecules associated with firmness (decreased activity of hydrolytic enzymes); as well as with degradation of chlorophyll (and synthesis of orange pigments) as has been suggested occurs in muskmelons fruit (Jiang et al., 2017). In this sense, some reports suggest such interactions between molecules applied to fruit and physiological responses (Sanchez-Gonzalez et al., 2011; Perdones et al., 2012,); or selective barrier effect for $\mathrm{CO}_{2}$ and/or oxygen on the chitosan coatings with essential oils added. The latter

Table 3: Disease incidence and severity index in papaya Maradol coated with chitosan films containing essential oils at 6 and 10 days of storage at room temperature

\begin{tabular}{|c|c|c|c|c|}
\hline \multirow[t]{2}{*}{ Treatment } & \multicolumn{2}{|c|}{ Disease incidence (\%) } & \multicolumn{2}{|c|}{ Severity index } \\
\hline & $6^{\text {th }}$ day & $10^{\text {th }}$ day & $6^{\text {th }}$ day & $10^{\text {th }}$ day \\
\hline Control (uncoated) & $35.71^{\mathrm{a}}$ & $83.33^{b}$ & 1 & 2 \\
\hline Fungicide (Mancozeb ${ }^{\circledR}$ ) & $14.29^{b}$ & $100^{\mathrm{a}}$ & 2 & 3 \\
\hline Cinnamon $2 \%$ & $14.29^{b}$ & $62.50^{c}$ & 1 & 2 \\
\hline Cinnamon $1 \%$-Lime $1 \%$ & $14.29^{b}$ & $75^{\mathrm{bc}}$ & 1 & 2 \\
\hline Cinnamon $1 \%$-Thyme $1 \%$ & $0^{c}$ & $25^{d}$ & 0 & 1 \\
\hline
\end{tabular}

Severity index: $0=$ non, $1=$ initially, $2=$ lightly moderate, $3=$ moderately and $4=$ severely damaged, values followed by the same letter for day are not significantly different $(p>0.05)$ determined by Duncan's range multiple test 

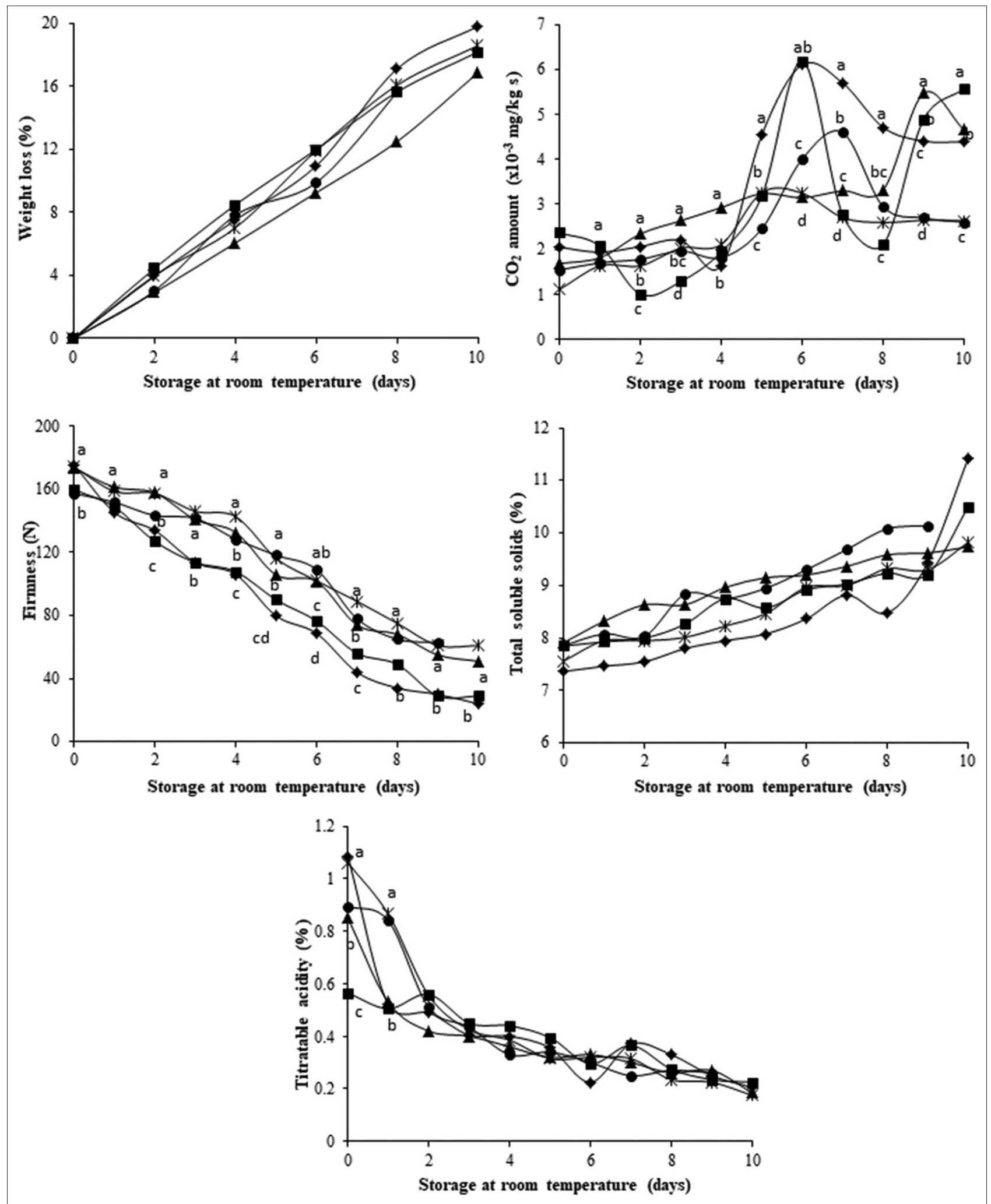

$\rightarrow$-Uncoated $\rightarrow$-Mancozeb $\$ \rightarrow$ Cinnamon $2 \% \rightarrow$-Cinnamon $1 \%$-Lime $1 \% \rightarrow$-Cinnamon $1 \%$-Thyme $1 \%$

Fig 2. Effect of coatings of chitosan enriched with essential oils on the physiological characteristics of papaya Maradol stored at room temperature. Means followed by the same letter at the same day of storage do not differ statistically $(p>0.05)$ from each other by Duncan's multiple range test. 

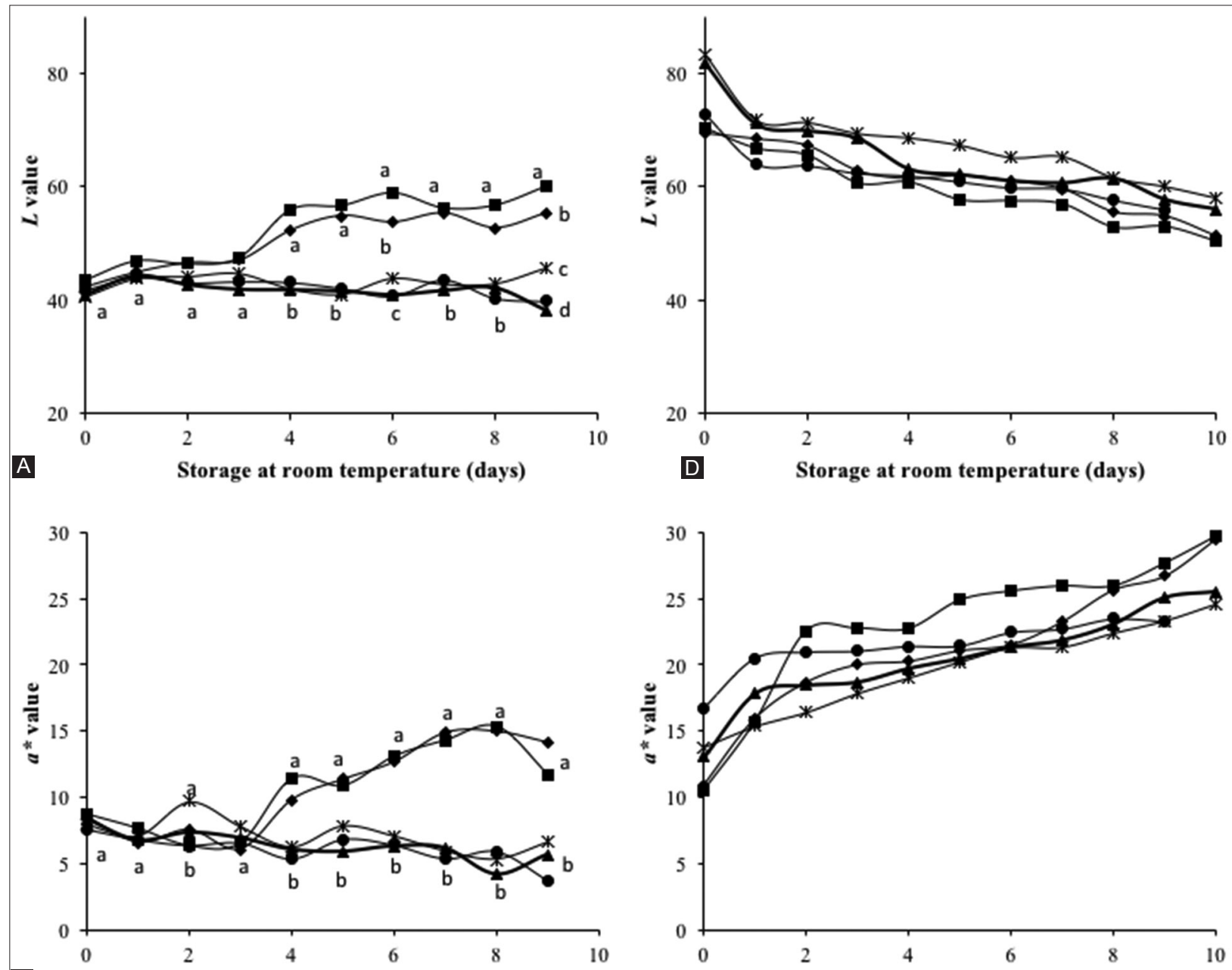

B

Storage at room temperature (days)

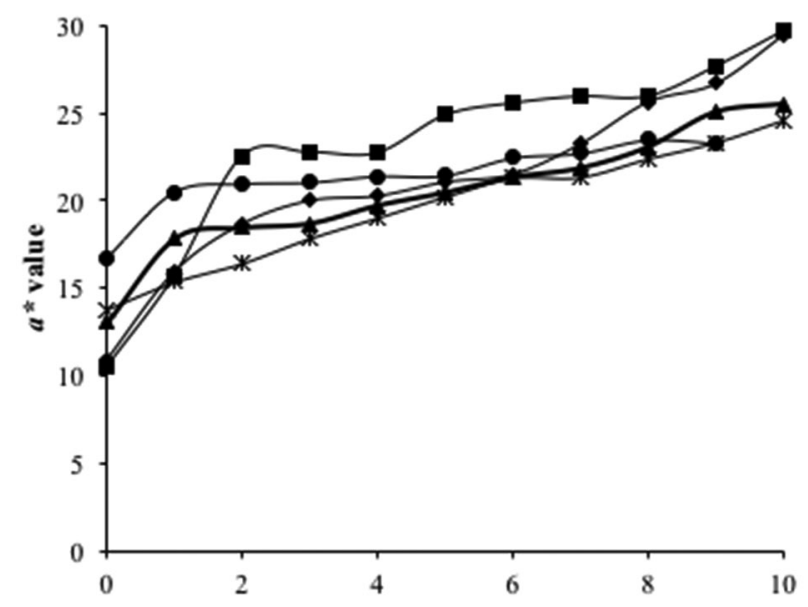

E Storage at room temperature (days)
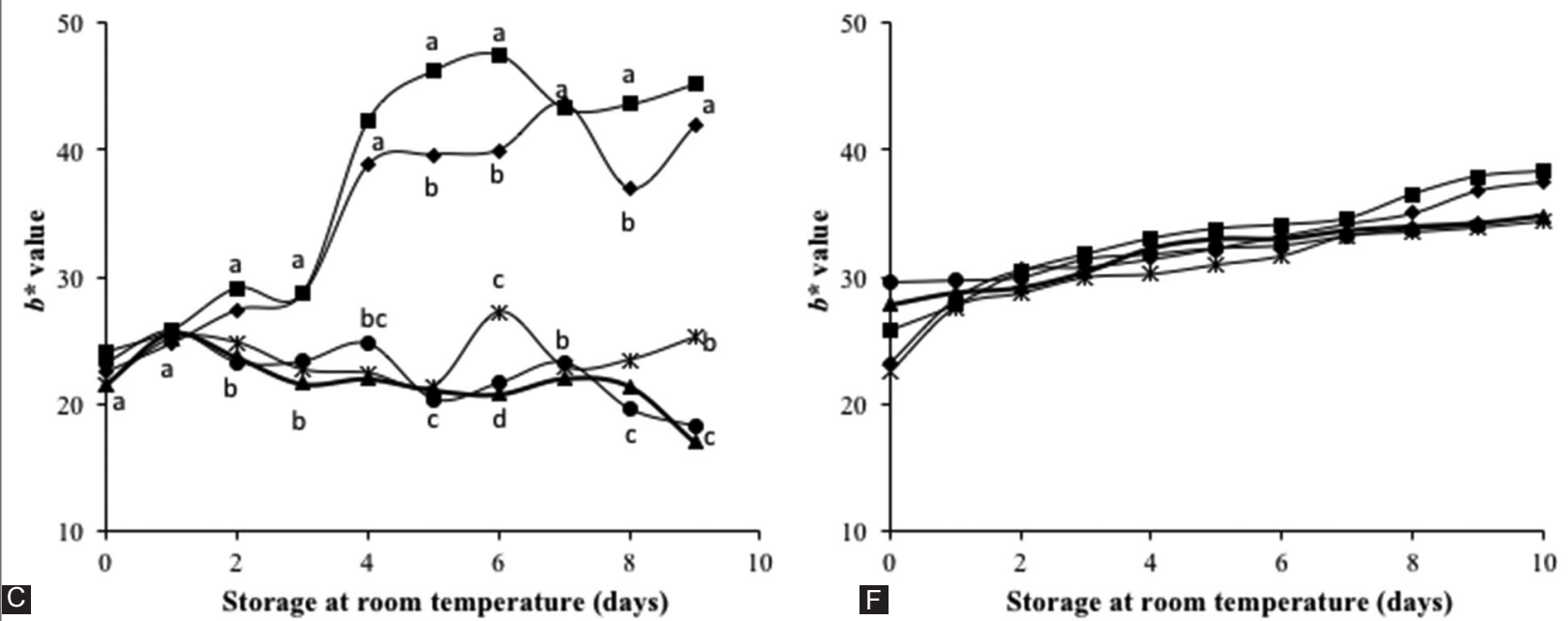

$\leftrightarrow$ Uncoated $\rightarrow$-Mancozeb ${ }^{\circledR} \nrightarrow$ Cinnamon $2 \%$

Cinnamon $1 \%$-Lime $1 \%$

*-Cinnamon 1\%-Thyme $1 \%$

Fig 3. Evolution of the peel (A-C) and pulp color (D-F) on papayas fruit coated with chitosan enriched with essential oils and stored at room temperature. $L^{*}$ (lightness), $a^{*}$ (chromaticity coordinate of yellow to blue), $b^{*}$ (chromaticity coordinate of green to red) values of the CIELab. Means followed by the same letter at the same day of storage do not differ statistically $(p>0.05)$ from each other by Duncan's multiple range test. 


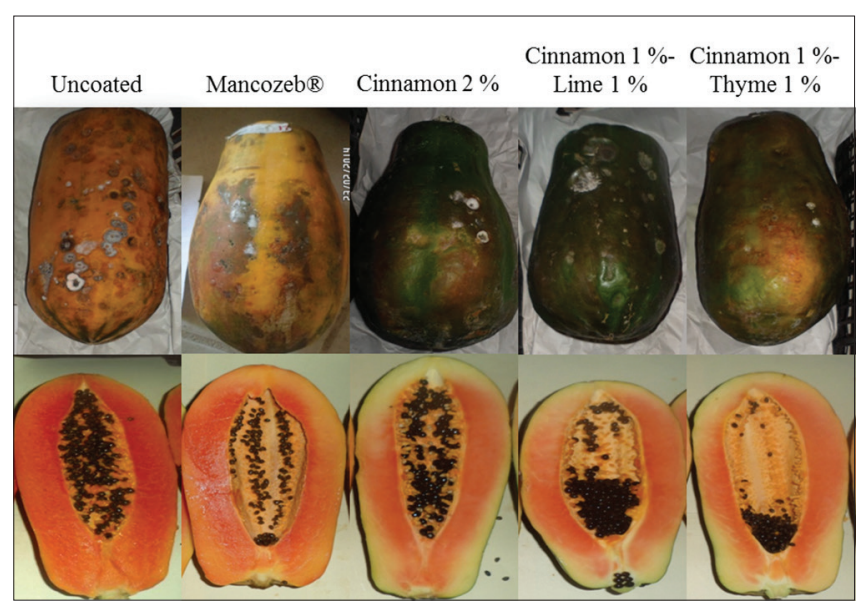

Fig 4. External and internal aspect of papaya fruit coated with chitosan enriched with essential oils at ten days of storage at room temperature.

may be supported by the solubility exhibited by the film coatings, where the film combined with cinnamon-thyme oil stands out showing the lowest solubility value (Table 2). This is associated with the lower mass transfer (Wang et al., 2011) and in this case, may be responsible for the lower transfer of $\mathrm{CO}_{2}$ to the outside or of oxygen to the interior of the fruit. The positive effect of coatings on parameters of respiration, color, and firmness found in our study is concordant with various experiments where the coatings are used in mango Ataulfo (Salvador-Figueroa et al., 2011), strawberries (Vu et al., 2011) and papaya Eksotika (Ali et al., 2011).

\section{Presence of fungi}

During the first four days of storage, none of the fruit showed visible fungal growth ( $0 \%$, data not shown). From $5^{\text {th }}$ day, the fruit treated with the fungicide Mancozeb $^{\circledR}$ showed a $6.25 \%$ incidence, while the rest continued without any presence (data not shown). On the $6^{\text {th }}$ day, only fruit coating with chitosan containing essential oil of cinnamon-thyme did not present incidence of fungi (Table 3). From that day until the $10^{\text {th }}$ day the trend was similar. Contrary to expectations, in this study the fungicide used showed no inhibitory effect on the development of fungi, quite contrarily, the incidence and severity in these fruits were greater than in fruit that received no treatment. This may be indicative of resistance, which has already been reported for Colletotrichum truncatum towards this synthetic carbamate (Zhang et al., 2017). At the end of the storage period, the fruit with coatings containing essential oil of cinnamon-thyme (1\%: $1 \%)$ showed the lowest value of incidence and severity among all treatments (Table 3). This difference was significant $(p<0.05)$. Although the coating containing essential oil of cinnamon showed activity against the fungus $C$. gloeosporioides in the in vitro test (greater inhibition area, Table 2); in the in situ test, the fungicidal effect was surrounded by the C1T1 coating, which shows a synergistic effect of the essential oils added to each other and added to the effect of chitosan on the growth of fungi to interact with peel of papaya fruit. Values very similar to the ones in this treatment (incidence $<50$; severity index $<2$ ) have been reported when essential oils of Mexican lime and thyme were applied in a pure state to papaya fruit (Bosquez-Molina et al., 2010). This could denote a greater contribution to this effect from thyme oil.

The fact that antifungal activity in vitro does not correlate with in situ activity (in fruits) is unexpected, due to the cinnamaldehyde, the main component of the cinnamon essential oil been suggested as strong fungi inhibitory agent (Xing et al., 2011) and their effect antifungal was significantly diminished when was applied in fruits. A phenomenon that has been reported to occur with some essential oils, is that being encapsulated reduces their inhibitory capacity (Perdones et al., 2012), which may show some interaction between oil, chitosan, and the components present in the peel of papaya fruit. It is also possible that there was interference by the presence of other opportunistic fungi in the in situ study because although the macroscopic morphology corresponded with C. gloeosporioides, the presence of opportunistic fungi associated with the pathogen is common. While essential oils evaluated here have shown effectiveness against various organisms (Xing et al., 2011; Perdones et al., 2012; Sanchez-Aldana et al., 2015), it is possible that cinnamon oil will prove limited in preventing the development of potential opportunistic fungi. Directed tests inoculating the fungal pathogen in the fruit before or after being coated can solve this question. Even with this, the protective effect of the coatings on the development and severity of fungi is superior to other fruit, which has reported the relatively low effect of bergamot essential oil on grapes stored at low temperatures (Sánchez-González et al., 2011a).

\section{CONCLUSION}

Films composite of chitosan enriched with essential oils of cinnamon, lime, and thyme, exhibited highly proper physical characteristics for application in papaya Maradol. The use of such films such as in papaya fruit coating did not affect the parameters of quality during fruit ripening at room temperature; on the contrary, its application on Maradol papaya promoted the lower rate of $\mathrm{CO}_{2}$ production and retained firmness in the papaya under ambient conditions of the humid tropic. Additionally, the chitosan coating containing $2 \%$ essential oils of cinnamon and lime $(1: 1 \mathrm{v} / \mathrm{v})$, was able to reduce the incidence of fungi on the fruit surface with values less than $25 \%$ for 10 days of storage, and also the severity of the infection. 
This coating prolongs the shelf life of papaya Maradol and may be proposed as an effective treatment postharvest papayas without the need for cold storage.

\section{ACKNOWLEDGMENTS}

This work was partly supported by SEP-Mexico through the program PROFOCIE-2014-07MSU0001H-11, purpose "Formación del Cuerpo Académico Biotecnología Alimentaria"; and by Consejo de Ciencia y Tecnología del Estado de Chiapas, Mexico.

\section{Author contributions}

M.S.F: conceived the experiment, contributed reagents/ materials/analysis tools, and reviewed drafts of the paper; D.C.L: performed the experiments, prepared figures and/ or tables, wrote the paper; L.A.A: contributed reagents/ materials/analysis tools, analyzed the data and reviewed drafts of the paper; D.G.L: performed the experiments, prepared figures and/or tables and reviewed drafts of the paper; R.R.Q: contributed reagents/materials/analysis tools, analyzed the data, and reviewed drafts of the paper; A.V.O: conceived and designed the experiments, performed the experiments, analyzed the data, prepared figures and/ or tables, wrote the paper.

\section{REFERENCES}

AOAC. 2010. In: Horwitz, W. and G. Latimer (Eds.), Official Methods of Analysis, Third Revision. $18^{\text {th }}$ ed. Association of Official Analytical Chemists, Maryland, USA.

Ali, A., T. Mahmud, K. Sijam and Y. Siddiqui. 2010. Effect of chitosan coatings on the physicochemical characteristics of eksotika II papaya (Carica papaya L.) fruit during cold storage. Food Chem. 124: $620-626$.

Santamaría-Basulto, S. F., E. Sauri-Duch, F. Espadas-Gil, R. Díaz-Plaza, A. Larqué-Saavedra and J. M. Santamaría. 2009. Postharvest ripening and maturity indices for maradol papaya. Interciencia. 34: 583-588.

Binsi, P. K., C. N. Ravishankar and T. K. Srinivasa-Gopal. 2013. Development and characterization of an edible composite film based on chitosan and virgin coconut oil with improved moisture sorption properties. J. Food Sci. 78: E526-E534.

Bosquez-Molina, E., E. Ronquillo, S. Bautista-Baños, J. R. Verde-Calvo and J. Morales-López. 2010. Inhibitory effect of essential oils against Colletotrichum gloeosporioides and Rhizopus stolonifer in stored papaya fruit and their possible application in coatings. Postharvest Biol. Tech. 57: 132-137.

Bourbon, A. I., A. C. Pinheiro, M. A. Cerqueira, C. M. R. Rocha, M. C. Avides, M. A. C. Quintas and A. A. Vicente. 2011. Physico-chemical characterization of chitosan-based edible films incorporating bioactive compounds of different molecular weight. J. Food Eng. 106: 111-118.

Casariego, A., M. A. Souza, J. A. Cerqueira, L. Teixeira, R. Cruz, A. Díaz and A. Vicente. 2009. Chitosan/clay films properties as affected by biopolymer and clay micro/nanoparticles concentrations. Food Hydrocoll. 23: 1895-1902.
Cia, P., S. F. Pascholati, E. A. Benato, E. C. Camili and C. A. Santos. 2007. Effects of gamma and UV-C irradiation on the postharvest control of papaya anthracnose. Postharvest Biol. Tech. 43: 366-373.

Cissé, M., J. Polidori, D. Montet, G. Loiseau and M. N. Ducamp-Collin. 2015. Preservation of mango quality by using functional chitosan-lactoperoxidase systems coatings. Postharvest Biol. Tech. 101: 10-14.

Dotto, G. L., M. L. G. Vieira and L. A. A. Pinto. 2015. Use of chitosan solutions for the microbiological shelf life extension of papaya fruit during storage at room temperature. LWT Food Sci. Technol. 64: 126-130.

Hosseini, M., S. Razavi and M. Mousavi. 2009. Antimicrobial, physical and mechanical properties of chitosan based films incorporated with thyme, clove and cinnamon essential oils. J. Food Process. Press. 33: 727-743.

Hu, M., D. Yang, D. J. Huber, Y. Jiang, M. Li, Z. Gao and Z. Zhang. 2014. Reduction of postharvest anthracnose and enhancement of disease resistance in ripening mango fruit by nitric oxide treatment. Postharvest Biol. Tech. 97: 115-122.

Jiang, C., P. Perkins-Veazie, G. Ma and C. Gunter. 2017. Muskmelon fruit quality in response to postharvest essential oil and whey protein sprays. Hortic. Sci. 52(6): 887-891.

Kaya, M., L. Česonienè, R. Daubaras, D. Leskauskaitè and D. Zabulionè. 2016. Chitosan coating or red kiwifruit (Actinidia melanandra) for extending of the shelf life. Int. J. Biol. Macromol. 85: 355-360.

Keqian, H., X. Jianghui, Z. Lubin, S. Dequan and G. Deqiang. 2012. Effects of chitosan coating on postharvest life and quality of guava (Psidium guajava L.) fruit during cold storage. Sci. Hortic. 144: 172-178.

Liu, W. W., H. Y. Qi, B. H. Xu, Y. Li, X. X. Tian, Y. Y. Jiang, X. X. Xu and D. Q. Lv. 2012. Ethanol treatment inhibits internal ethylene concentrations and enhances ethyl ester production during storage of oriental sweet melons (Cucumis melo var. Makuwa Makino). Postharvest Biol. Tech. 67: 75-83.

López-Mata, M., S. Ruiz-Cruz, N. Silva-Beltrán, J. Ornelas-Paz, P. Zamudio-Flores and S. Burruel-Ibarra. 2013. Physicochemical, antimicrobial and antioxidant properties of chitosan films incorporated with carvacrol. Molecules. 18: 13735-13753.

Lopez-Reyes, J. G., D. Spadaro, A. Prelle, A. Garibaldi and M. L. Gullino. 2013. Efficacy of plant essential oils on postharvest control of rots caused by fungi on different stone fruit in vivo. J. Food Prot. 76: 631-639.

Ma, Q., Y. Zhang, P. Critzer, P. M. Davidson, S. Zivanovic and Q. Zhong. 2016. Physical, mechanical, and antimicrobial properties of chitosan films with microemulsions of cinnamon bark oil and soybean oil. Food Hydrocoll. 52: 533-542.

Oliveira, B. F., A. F. Cruz and E. Alves. 2016. Cassava starch coatings for postharvest control of papaya anthracnose. Phytopathol. Mediterr. 55(2): 276-284.

Peng, Y. and Y. Li. 2014. Combined effects of two kinds of essential oils on physical, mechanical and structural properties of chitosan films. Food Hydrocoll. 36: 287-293.

Perdones, A., L. Sánchez-González, A. Chiralt and M. Vargas. 2012. Effect of chitosan-lemon essential oil coatings on storage-keeping quality of strawberry. Postharvest Biol. Tech. 70: 32-41.

Pereda, M., G. Amica and N. Marcovich. 2012. Development and characterization of edible chitosan/olive oil emulsion films. Carbohyd. Polym. 87: 1318-1325.

Pereira, E., A. Santos, F. Reis, R. M. Tavares, P. Baptista, T. Lino- 
Neto and C. Almeida-Aguiar. 2013. A new effective assay to detect antimicrobial activity of filamentous fungi. Microbiol. Res. 168: $1-5$.

Perez-Espitia, P. J., N. F. Ferreira-Soares, L. C. Moreira-Botti, N. Ramos-De Melo, O. Liparini-Pereira and W. Azevêdo-Da Silva. 2012. Assessment of the efficiency of essential oils in the preservation of postharvest papaya in an antimicrobial packaging system. Braz. J. Food Technol. 15: 307-316.

Rashid, M. H. A., B. W. W. Grout, A. Continella and T. M. M. Mahmud. 2015. Low-dose gamma irradiation following hot water immersion of papaya (Carica papaya Linn.) fruit provides additional control of postharvest fungal infection to extend shelf life. Radiat. Phys. Chem. 110: 77-81.

Sánchez-Aldana, D., S. Andrade-Ochoa, C. Aguilar, J. Contreras-Esquivel and G. Nevárez-Moorillón. 2015. Antibacterial activity of pectic-based edible films incorporated with Mexican lime essential oil. Food Control. 50: 907-912.

Sánchez-González, L., C. Pastor, M. Vargas, A. Chiralt, C. González-Martínez and M. Cháfer. 2011a. Effect of hydroxypropylmethylcellulose and chitosan coatings with and without bergamot essential oil on quality and safety of coldstored grapes. Postharvest Biol. Technol. 60: 57-63.

Sánchez-González, L., M. Vargas, C. González-Martínez, A. Chiralt and M. Cháfer. 2011b. Use of essential oils in bioactive edible coatings: A review. Food Eng. Rev. 3: 1-16.

Salvador-Figueroa, M., W. Aragón-González, E. Hernández-Ortiz, A. Vázquez-Ovando and M. Adriano-Anaya. 2011. Effect of chitosan coating on some characteristics of mango (Mangifera indica L.) "Ataulfo" subjected to hydrothermal process. Afr. J. Agric. Res. 6: 5800-5807.
Singh, S. P. and D. V. Sudhakar. 2011. Papaya (Carica papaya L.) In: Yahia, E. M., (Ed.), Postharvest Biology and Technology of Tropical and Subtropical Fruits, Mangosteen to White Sapote. Vol. 4. Woodhead Publishing, Philadelphia, USA. p. 536.

Sivakumar, D. and S. Bautista-Baños. 2014. A review on the use of essential oils for postharvest decay control and maintenance of fruit quality during storage. Crop Prot. 64: 27-37.

Ulbin-Figlewicz, N., A. Zimoch-Korzycka and A. Jarmoluk. 2014. Antibacterial activity and physical properties of edible chitosan films exposed to low-pressure plasma. Food Bioprocess Tech. 7: 3646-3654.

Vu, K. D., R. G. Hollingsworth, E. Leroux, I. S. Salmier and M. Lacroix. 2011. Development of edible bioactive coating based on modified chitosan for increasing the shelf life of strawberries. Food Res. Int. 44: 198-203.

Wang, L., F. Liu, Y. Jiang, Z. Chai, P. Li, Y. Cheng, H. Jing and X. Leng 2011. Synergistic antimicrobial activities of natural essential oils with chitosan films. J. Agric. Food Chem. 59: 12411-12419.

Xing, Y., X. Li, Q. Xu, J. Yun, Y. Lu and Y. Tang. 2011. Effects of chitosan coating enriched with cinnamon oil on qualitative properties of sweet pepper (Capsicum annuum L.). Food Chem. 124: $1443-1450$.

Zeng, H., X. Chen and J. Liang. 2015. In vitro antifungal activity and mechanism of essential oil from fennel (Foeniculum vulgare L.) on dermatophyte species. J. Med. Microbiol. 64: 93-103.

Zhang, C., Y. Diao, W. Wang, J. Hao, M. Imran, H. Duan and X. Liu. 2017. Assessing the risk for resistance and elucidating the genetics of Colletotrichum truncatum that is only sensitive to some DMI fungicides. Front. Microbiol. 8: 1779. 